\title{
EFFECT OF PROPORTION OF HOME AND EXTERNAL SCRAP ON THE MECHANICAL PROPERTIES OF RECYCLED PVC: A COMPARATIVE STUDY
}

\author{
M. Jalal Uddin, Fahmida Gulshan and ASW Kurny \\ Department of Materials and Metallurgical Engineering \\ Bangladesh University of Engineering and Technology, \\ Dhaka, Bangladesh. \\ Email: aswkurny@mme.buet.ac.bd \\ Phone: Fax: 00888613046
}

\begin{abstract}
Raw material powder mixtures have been prepared with PVC resin, unplasticized polyvinylchloride (uPVC) scrap and additives. A twin screw extruder has been used to make pipe for sample preparation from the mixture. Domestic and external uPVC scrap were formulated and blended with PVC resin to form melt compound. Domestic samples designated as DS-10, DS-20, DS-30, DS-40, DS-50 and DS-100 have been prepared by blending 10, 20,30, 40, and $50 \mathrm{phr}$ and 100\% uPVC domestic scrap with PVC resin and various additives, followed by extrusion, flattening and machining. Following a similar procedure, external samples such as ES-10, ES-20, ES-30, ES-40, ES-50 and ES-100 have been prepared using external uPVC scrap. The effects of the proportions of UPVC scrap in the raw material mix on the mechanical properties such as break stress (BS), \% elongation at break, flexural yield strength [1], impact strength (IS) and Shore hardness were investigated. The maximum decrease in break stress is $11.40 \%$ for $20 \mathrm{phr}$ domestic scrap, while in samples containing external scrap this decrease is $15.71 \%$ for $40 \mathrm{phr}$ scrap. The minimum and maximum reduction in IS values of DS are recorded $1.0 \%$ for DS-10 and $27.4 \%$ for DS-40, respectively, whereas the minimum and maximum decrease in IS values of ES recorded are 9.6\% for ES-10 and 39.2\% for ES50 , respectively. The minimum and maximum increase in hardness values of DS are recorded as $0.07 \%$ for DS-40 and $2.8 \%$ for DS-10, respectively, whereas the minimum and maximum reduction in hardness values of ES are recorded as $1.2 \%$ for ES-50 and $2.2 \%$ for ES-20, respectively. The mechanical properties of samples were found to deteriorate with increasing quantity of scrap in the raw material mix, the effects of external scrap being more prominent.
\end{abstract}

Keywords: uPVC; recycled scrap; mechanical properties; density.

\section{INTRODUCTION}

Polyvinylchloride (PVC) is one of the major thermoplastics materials. PVC has a fair degree of resistance against environment, water and chemicals. In addition, PVC has good surface characteristics and appearance, light weight, strength and low cost. The main applications of PVC are in the building sector, which accounts for $57 \%$ of all uses; PVC is also used in many other applications such as household appliances (18\%), packaging (9\%), electric and electronic equipment (7\%), automotive equipment (7\%), furniture (1\%) and other applications (1\%) [2]. Usage of plastics is growing day by day 
and has consequently created the problem of waste disposal. The problem has multiplied because plastics are non-biodegradable. Proper disposal of the waste has led to social and environmental arguments [3]. Recycling minimizes the amount of plastics wastes to be disposed of and thus reduces the environmental problems [4]. Recycling of plastics uses less energy than is consumed in virgin resin production and thus competes strongly with virgin resins [5].

Most spent PVC products used to be disposed of via either landfill or incineration. In a sanitary landfill, PVC wastes may contaminate ground water due to leaching of pigments/dye stuff in the waste plastics products. Plastics in a landfill also hinder water filtration. Soil compactness is also hindered by throw-away plastics. In incineration, PVC burns much like other organic materials. Harmful gases (greenhouse gas, $\mathrm{HCl}$, etc.) are emitted to the atmosphere from burning PVC [6]. Thus the disposal of spent plastics is viewed as a matter of environmental concern. In recent years recycling is being promoted as a means to address the disposal problem. At the same time, recycling of plastics helps preserve natural resources and reduces consumption of energy and emissions of $\mathrm{CO}_{2}, \mathrm{NO}$ and $\mathrm{SO}_{2}$ gases. Recycling of plastics is a challenging task [7-10], particularly in view of the diversity of sources of waste plastics, higher potential for contamination of plastics wastes and a wide range of requirements for the intended products. There are two ways of recycling. These are mechanical recycling and chemical or feedstock recycling. Mechanical recycling refers to processes which involve sorting, melting, shredding or granulation of waste plastics. Most of the work on mechanical recycling has concentrated on separation of the different types of plastics as a pretreatment for recycling [7, 8], raw materials burdening [11], and thermal degradation of plastics [12]. Chemical or feedstock recycling involves a range of plastic recovery techniques which break down polymers into their constituent monomers. Chemical recycling technologies include pyrolysis [13], gasification [14] and thermal cracking $[15,16]$. Mechanical recycling is a physical method, in which the plastic wastes are freed of contaminants, washed and dried and then formed into flakes, granulates or pellets of appropriate quality. These are then melted to make new products by extrusion [17]. The best results are obtained when the scrap contains just one kind of polymer. The processability, rheology, thermal, mechanical and morphological properties of three different commercial PVC compounds blended with post-consumer PVC bottles and PVC cables were examined with respect to the recycled PVC content [18]. It was concluded that the optimum concentrations of PVC recyclates to be added to virgin PVC compounds were different from one property to another and also depended on the type of virgin PVC grade used. A study [19] of the processing characteristics and mechanical properties of multiple recycled rigid PVC has shown that re-extrusion of old materials gives profiles with almost the same tensile properties as for the new profiles, provided contamination is addressed. A comparison of the effects on the mechanical properties of addition of recycled post-consumer PVC waste in the forms of flake and powdered material to virgin bottle compound has shown that recycled flake material causes an appreciable reduction in strength properties, which has been attributed primarily to large impurity particles [20]. The mechanical and processing properties of recycled PVC from bottles and pipes were compared with those of virgin pipe grade PVC [21]. It was found that the particle size and the re-stabilization of the recycled PVC are the two main points to be considered for obtaining virgin/recycled PVC blends with uniform and good mechanical properties. The variation in important properties of PVC floorings during their service life owing to ageing processes, and how these variations influence their suitability as post-consumer 
products for mechanical recycling was investigated. It was shown that plastic wastes can be mechanically recycled in the form in which they were recovered without upgrading and without the addition of new plasticizer.

This work aims to compare the effects of home scrap and external scrap on the tensile and flexural properties, impact strength and hardness of specimens prepared from mixtures of domestic scrap and external scrap with virgin uPVC powder. The main objective of this study is to assess the change of quality of the products produced from the dry and melt mixture of ingredients of virgin polyvinylchloride (PVC) powder with varied amounts of domestic and external polyvinylchloride scrap in terms of mechanical properties.

\section{EXPERIMENTAL DETAILS}

uPVC scrap materials were collected from within the premises. Scrap was also collected from local vendors and sorted from other scrap materials by visual examination, manufacturer's labeling code, end use and flame test. Scrap PVC from these two different sources was separately shredded by using a crusher machine followed by pulverization by a pulverizing machine. Measured quantities (Table 1) of additives, base resin and scrap PVC powder were mixed thoroughly in both hot and cold mixers before being discharged for extrusion. Two different sets of samples were made, one set containing scrap from within the premises and the other set containing external scrap. Per hundred resin (phr) has been used as the measuring unit of additives and scrap PVC. Four inches nominal diameter pipes of different compositions (Table 1) were then extruded. The extruded pipes were immersed in chilled water at temperature $15^{\circ} \mathrm{C} .180$ $\mathrm{mm}$ long pieces were cut with a circular saw along the longitudinal direction of the extruded uPVC pipe. The specimens were heated in an electric oven at a temperature of $80^{\circ} \mathrm{C}$ for 45 minutes. The specimens were then flattened by placing the hot piece between two glass pieces and pressed by an approximately $20 \mathrm{~kg}$ load for 2 hours. The straightened plates were used to make test specimens by computerized numerical control (CNC) machining.

Table 1. Formulations attempted (phr) with both home and external scrap.

\begin{tabular}{llllllll}
\hline Sample & A & B & C & D & E & F & G \\
\hline vPVC $(\mathrm{kg})\left(-\mathrm{CH}_{2} \mathrm{CHCl}-\right)$ & 100 & 100 & 100 & 100 & 100 & 100 & -- \\
Filler $(\mathrm{CaCO}) \mathrm{kg}$ & 25.0 & 25.0 & 25.0 & 25.0 & 25.0 & 25.0 & -- \\
Stabilizer $\left(3 \mathrm{PbO} . \mathrm{PbSO}_{4} \cdot \mathrm{H}_{2} \mathrm{O}\right)$ & 2.60 & 2.60 & 2.60 & 2.60 & 2.60 & 2.60 & -- \\
$(\mathrm{kg})$ & & & & & & & \\
Stearic acid $(\mathrm{kg})\left(\mathrm{C}_{17} \mathrm{H}_{35} \mathrm{COOH}\right)$ & 0.20 & 0.20 & 0.20 & 0.20 & 0.20 & 0.20 & -- \\
uPVC-scrap $(\mathrm{kg})$ & 0.00 & 10.0 & 20.0 & 30.0 & 40.0 & 50.0 & $100 \%$ \\
Carbon $(\mathrm{C})-$-black $(\mathrm{kg})$ & 0.08 & 0.08 & 0.08 & 0.08 & 0.08 & 0.08 & -- \\
Pigment $\left(\mathrm{TiO}_{2}\right)$ & 0.60 & 0.60 & 0.60 & 0.60 & 0.60 & 0.60 & -- \\
\hline
\end{tabular}

During the cutting operation, coolant was used to control heat generation so that no degradation of the specimen material occurred. At the end of machining, the burrs remaining in the edges were removed using a hairbrush. All the surfaces of the specimen were inspected with a magnifying glass to detect any flaws, scratches or imperfections. All the surfaces were smoothened with 00 -abrasive paper. The specimens for tension, flexural and impact tests and for hardness measurements were kept at a 
temperature of $23 \pm 2{ }^{\circ} \mathrm{C}$ and relative humidity of $50 \pm 5 \%$ for $48 \mathrm{hrs}$ before testing. Testing was performed in the same atmosphere of temperature $23 \pm 2^{\circ} \mathrm{C}$ and relative humidity $50 \pm 5 \%$. The technical quality was determined by measurement of break stress, elongation at break, impact strength and hardness. The test procedures are summarized in Table 2.

Table 2. Summary of the different mechanical tests performed as per standards.

\begin{tabular}{|c|c|c|c|c|c|}
\hline \multirow{2}{*}{$\begin{array}{l}\text { Name of } \\
\text { test }\end{array}$} & \multirow{2}{*}{$\begin{array}{l}\text { Number } \\
\text { of samples } \\
\text { tested }\end{array}$} & \multicolumn{2}{|c|}{ Direction of test } & \multirow[t]{2}{*}{ Test condition } & \multirow{2}{*}{$\begin{array}{l}\text { Standard } \\
\text { followed }\end{array}$} \\
\hline & & $\begin{array}{l}\text { Longitu } \\
\text { dinal }\end{array}$ & $\begin{array}{l}\text { Transve } \\
\text { rse }\end{array}$ & & \\
\hline Tension & 14 & 07 & 07 & $\begin{array}{l}\text { Cross-head speed: } 5 \\
\mathrm{~mm} / \mathrm{min}\end{array}$ & $\begin{array}{l}\text { ASTM } \\
\text { D 638M } 14\end{array}$ \\
\hline Flexural & 10 & 05 & 05 & $\begin{array}{l}\text { Load on mid-span of } \\
\text { a simple beam } \\
\text { Cross-head speed: } 5 \\
\mathrm{~mm} / \mathrm{min} \text {. }\end{array}$ & $\begin{array}{l}\text { ASTM } \\
\text { D790-03 }\end{array}$ \\
\hline Impact & 20 & 10 & 10 & $\begin{array}{l}\text { Izod impact } \\
\text { notch side of the } \\
\text { specimen was struck } \\
\text { by the blow }\end{array}$ & $\begin{array}{l}\text { ASTM } \\
\text { D256-06 }\end{array}$ \\
\hline $\begin{array}{l}\text { Shore } \\
\text { Hardness }\end{array}$ & 5 & - & - & $\begin{array}{l}\text { Indenters: D type } \\
\text { Distance between } \\
\text { indentations: } 5 \mathrm{~mm} \\
\text { Distance from edge: } \\
13 \mathrm{~mm}\end{array}$ & $\begin{array}{l}\text { ASTM } \\
\text { D2240-81 }\end{array}$ \\
\hline
\end{tabular}

\section{Tensile Strength}

\section{RESULTS AND DISCUSSION}

Figure 1 represents how break stress (BS) and \% elongation at break vary with the composition of DS and ES. The BS value of the CS-0 sample is found to be 34.1 MPa. It seems to decrease gradually with the increase of DS content. However, the minimum BS value is observed for the sample DS-20, which is $30.2 \mathrm{MPa}$. Thus, the estimated maximum decrease in $\mathrm{BS}$ is $11.4 \%$. On the other hand, the strain \% also decreases with the increase of DS content. Similarly, break stress and \% elongation at break decrease by 38.9 and $45.8 \%$ with addition of $100 \%$ external scrap. From these data, it can be stated that the deterioration of BS and strain\% for domestic scrap loaded PVC are lower than those for external scrap loaded PVC. Break stress is strongly influenced by the number of monomers present in the large molecules or the molecular weight and its distribution [21, 22]. In general, domestic scrap is less contaminated and within a short time this type of scrap is consumed. On the contrary, external scrap is highly contaminated and most of the external scrap has been exposed to ultraviolet rays, sunlight and mechanical stress for a long time. External scrap also faces weathering effects. These factors accelerate to break large molecules of scrap into smaller molecules. From the above discussion it can be stated that the decrease in break stress and $\%$ elongation at break may be attributed to the contamination present in the scrap and the breaking of large molecules into smaller molecules. However, the values obtained in break stress and \% elongation at break show some fluctuations in both sets 
of samples. This may be a lack of compatibility or may be related to gelation of ingredients.

Both the decrease and fluctuation of BS and strain\% have been investigated elsewhere [20], where the authors have found similar changes in the mechanical properties of PVC during their study on the recycling of PVC bottle compounds. This fact was also reported by Strapasson et al. [23], who studied the tensile and impact behavior of polypropylene/low density polyethylene blends. In their study a linear variation of the yield strength and elastic modulus with the blend composition was observed. An irregular behavior of the blend was also reported. Generally, with increasing BS, \% elongation at break decreases. It is seen that with decreasing $\mathrm{BS}, \%$ elongation at break is also decreasing. This effect is controlled by the addition of the required amount of $\mathrm{CaCO}_{3}$, which imparts ductility. There is also an optimum value of $\mathrm{CaCO}_{3}$ addition beyond which the BS starts to decline. So optimization of BS and \% elongation at break through proper formulation is an important issue to produce good quality pipe products.
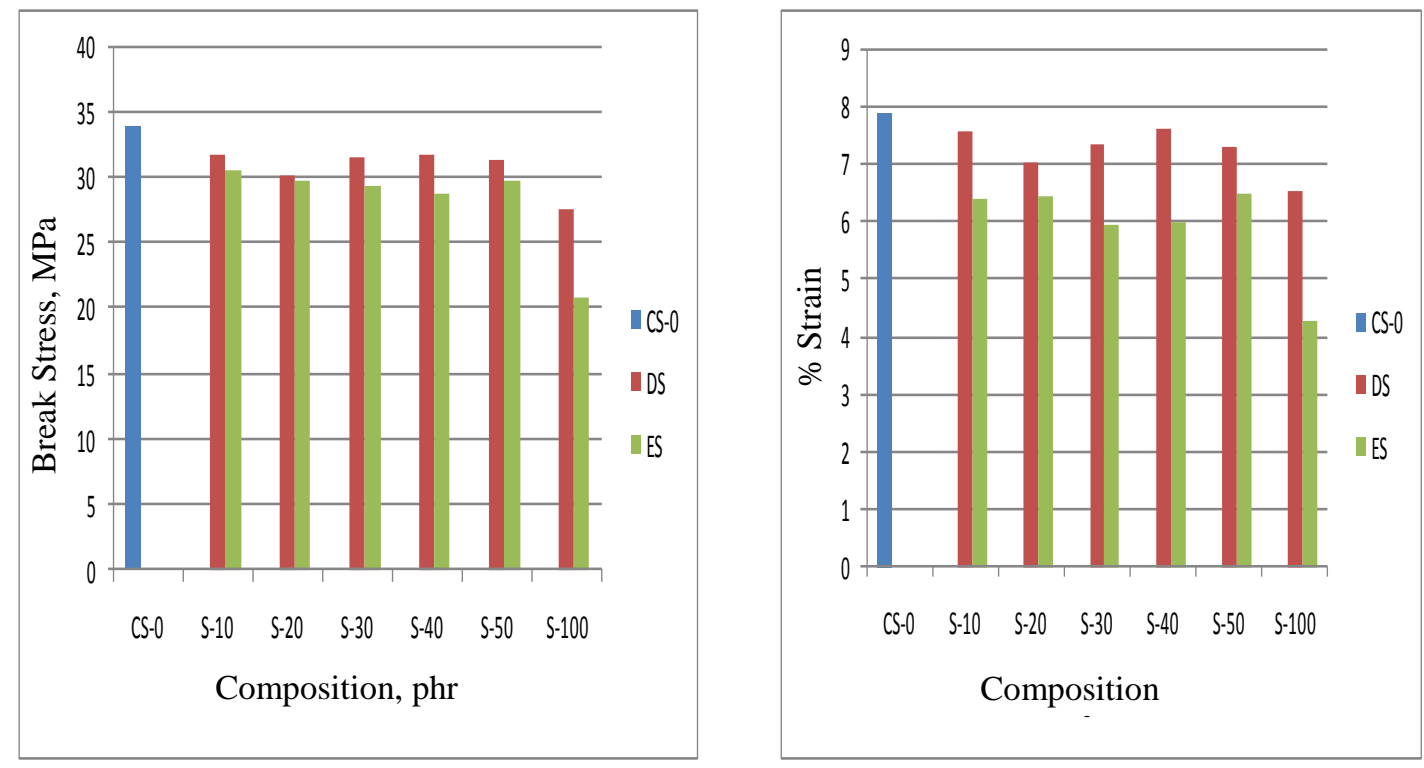

Figure 1. (a) Variation of break stress with composition of uPVC; (b) Variation of strain with composition of uPVC.

\section{Flexural Strength}

The results of flexural testing are shown in Figure 2. The flexural yield stress [1] value of the CS-0 sample is found to be $52.7 \mathrm{MPa}$. The FYS fluctuates with addition of domestic and external scrap. The maximum increase and decrease of FYS of domestic samples are $11.3 \%$ for DS-30 and 5.8\% for DS-100, respectively. On the other hand, the maximum decrease of FYS of external samples is $35.5 \%$ for ES-100. From these data, it can be observed that the deterioration of FYS for DS loaded PVC is lower than that for ES loaded PVC. FYS of samples containing 20, 40 and 50 phr uPVC scrap is almost identical to the samples containing no uPVC scrap. Although there is fluctuation in flexural strength, the overall trend is decreasing in FYS with scrap addition in both cases. Basically, flexural strength is the combination of tensile strength and compressive strength. So the same reasons mentioned in the tensile test may be applicable to explain 
the decreasing and fluctuating nature in flexural strength. Figure 2 also shows that the reduction in FYS of samples having external scrap is more pronounced compared to samples containing domestic scrap. It is also seen that for samples DS-10 and DS-30, the FYS has increased compared to the samples containing no scrap. This may be due to good compatibility and gelation of ingredients.

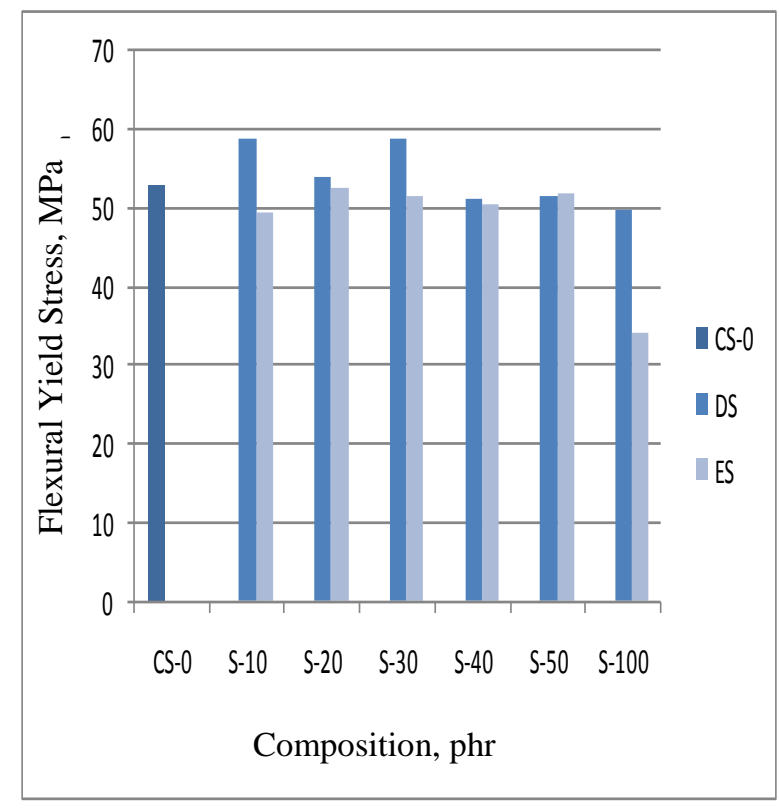

Figure 2. Variation of flexural strength with composition

\section{Impact Strength}

Figure 3 illustrates the variation of impact strength with the quantity of scrap in the raw material mix. The impact strength value of the CS-0 sample is found to be $47 \mathrm{~kJ} / \mathrm{m}^{2}$. The impact strength values show some fluctuations. The minimum and maximum reduction in impact strength values of domestic samples are recorded as $1.0 \%$ for DS-10 and $27.4 \%$ for DS-40, respectively, whereas the minimum and maximum decrease in impact strength values of external samples are recorded as $9.6 \%$ for ES-10 and 39.2\% for ES-50, respectively. It is clear that external scrap affects the impact properties to a greater extent than domestic scrap. It has also been found that the impact strength value decreases by 9.6 and $35.9 \%$ with $100 \%$ domestic and external scrap, respectively. From these data, it can be concluded that the impact strength of samples containing external scrap deteriorates more than that of the samples containing domestic scrap. This may be due to the presence of inhomogeneity, a lack of compatibility and impurities in the mixture. Besides, differences in the sizes and shapes of filler and other additives used by different industries may be responsible for the reduction of the impact values of both domestic and external samples. The values obtained in impact strength show some fluctuations in both sets of samples, which may be attributed to differences in the sizes and shapes, and the amount of fillers mixed in the raw materials mix. Below the glass transition, molecular movement is restricted due to the presence of different ingredients. As a result, impact strength is reduced and sometimes fluctuates. Similar effects have been observed by Fillot et al. [24]. 


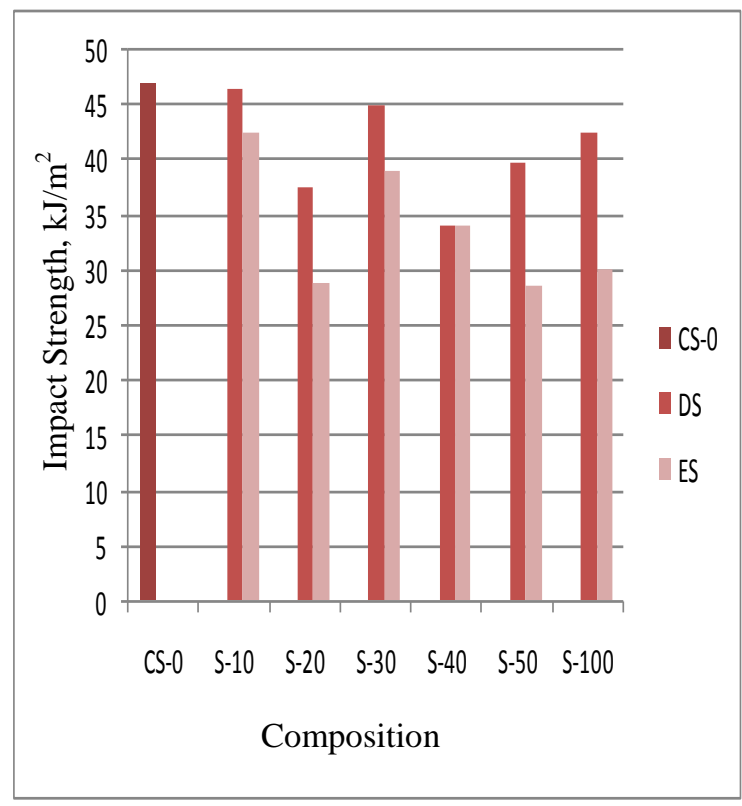

Figure 3. Variation of impact strength with composition.

\section{Hardness Test}

Figure 4 displays the variation of hardness with the quantity of scrap mixed with the PVC resin and additives. The hardness value of the CS- 0 sample is found to be 75.25 Shore-D. The hardness values show minor fluctuations. The minimum and maximum increase in hardness values of domestic samples are recorded to be $0.07 \%$ for DS-40 and $2.8 \%$ for DS-10, respectively, whereas the minimum and maximum reduction in hardness values of external samples are recorded to be $1.2 \%$ for ES-50 and $2.2 \%$ for ES-20, respectively. It has also been found that the hardness value increases by $0.3 \%$ and decreases by $1.8 \%$ with addition of $100 \%$ domestic and external scrap, respectively. It can also be seen that the increasing effect of the hardness value is more pronounced in the case of external scrap. In analyzing the increase or decrease of the hardness values of the samples containing domestic and external scrap, it can be seen that the difference in hardness is low. From this data analysis it can be concluded that hardness does not depend on the amount of scrap added. The small variation of hardness may be due to a lack of homogeneous dispersion of fillers and additives in the polymer matrix.

The results of hardness are in good agreement with Sombatsompop et al. [18], who studied the processability and properties of post-consumer polyvinylchloride scrap. They observed that hardness and density remain unaffected by the addition of scrap. It is also concluded that the optimum concentrations of PVC recyclates to add to PVC resin and additives are different from one property to another and also dependent on the type of PVC resin grade. To explain the results obtained in the tensile, flexural and impact tests the following reasons may be considered. PVC contains organic and inorganic ingredients and is a highly unstable material. To prevent degradation during transportation and storage, organic additives including plasticizers are added. Different companies use formulations of filler $\left(\mathrm{CaCO}_{3}\right)$, processing aids and stabilizers of different types and amounts. Thus there is a complex compositional variation in the PVC compound. The compositional variation can affect the compatibility among different ingredients and thus lead to variation in properties. 


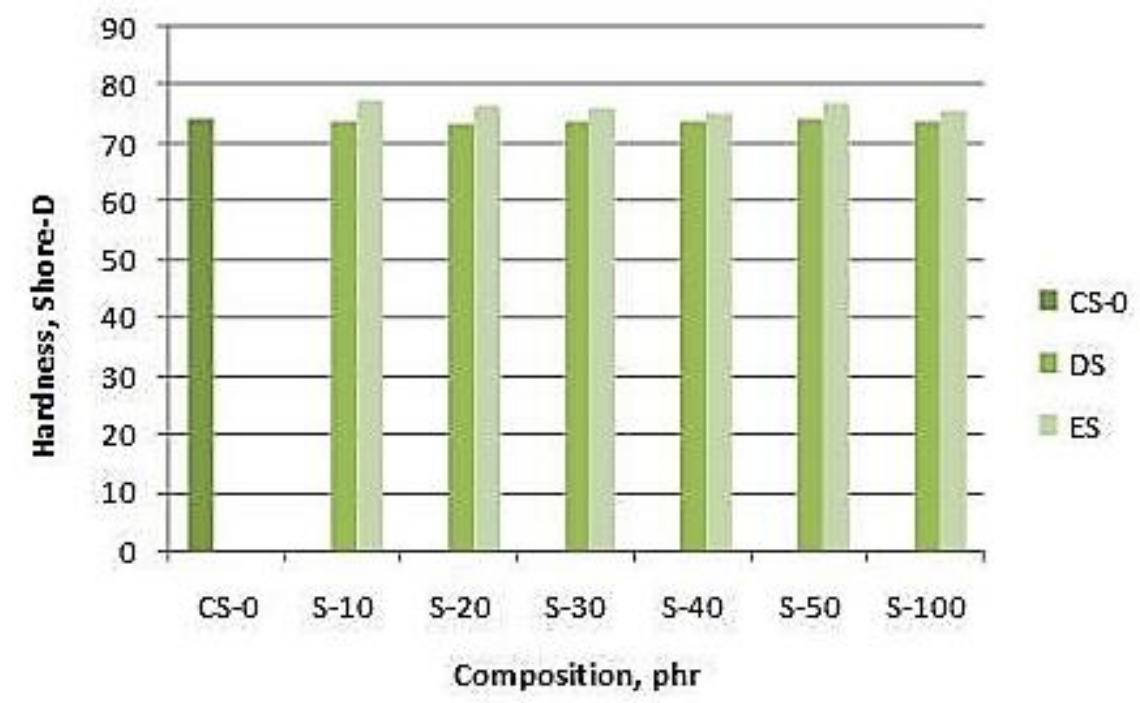

Figure 4. Variation of hardness with composition

Different recipes are used for different grades of pipe. Different grades of pipe are manufactured in the same industry or in different industries. During recycling different grades of pipe are cut, crushed and pulverized. So there is a possibility of variation in ingredients from different batches and also from different industries. Besides, long exposure to the environment can contaminate the products with foreign particles. Recipe variation along with contamination has ultimately affected the mechanical properties, which have been reflected as fluctuation in properties. The scrap had different prior histories of processing, and heating to different temperatures during processing may have caused variations in gelation or fusion. Gelation to different extents may be another cause of property variation. Since PVC is a viscoelastic organic material, its properties change with time, temperature and weathering effects. The scrap has different prior histories and there was time variation and weathering effects on the scrapped PVC which affected the nature of the scrap. This type of change in mechanical properties has also been reported by Wenguang et al. [25], who investigated the processing and mechanical properties of recycled PVC and of homopolymer blends with virgin PVC.

Ditta et al. [19] carried out a study on the processing characteristics and mechanical properties of multiple recycled rigid PVC. In their investigation it was observed that for outdoor profiles, the elongation at break does not change significantly even after 20 years of service life compared to the values when new material is used. Re-extrusion of old materials gives profiles with almost the same tensile properties as for the new profiles, provided contamination is addressed. The type and amount of contaminations vary with time and the environment to which the scrap was exposed. Such contamination is one of the most important causes that affect the quality of products and a variation in the quantity of contaminants may cause a fluctuation in properties. Different industries use different types of extruder. Even when the same recipes are used, the quality will be different for different models of extruder. Although in this research work the same extruder has been used to prepare the samples, the scrap used may not have been produced by the same type of extruder. Before blending of ingredients with scrap materials, the scrap components were shredded and pulverized. Different models of crusher and pulverizing unit are available in the world, due to which the grain size of powder is also different. Even small differences can be 
significant, especially where fine fillers are involved. The particle size distribution is also significant. In short, it can be said that the quality of the technology used also affects the quality of the products. Variation in the technology used may also be an important cause of decreasing the quality of products with fluctuation.

Yarahmadi et al. [5] investigated profiles made of rigid PVC after different numbers of repeated extrusions to check changes of properties and durability. They found an improvement of mechanical properties after the second extrusion. This was explained by an increase in the degree of gelation of the PVC material. They also found that the estimated lifetime, for indoor use at room temperature, of materials that were extruded five times was one-third of the lifetime of the materials that were extruded only once. The crystallinity of a material influences many of its characteristics, including mechanical strength, opacity, and thermal properties. With increasing crystallinity up to a certain limit, tensile strength increases and then decreases. With increasing crystallinity, impact strength also decreases. Fluctuation in crystallinity may also affect mechanical properties.

\section{Surface Morphology and Elemental Analysis}

Scanning Electron Microscopy (SEM) was used to investigate the morphological properties of the fractured surfaces of samples designated as CS-0, DS-10, DS-20, DS30, DS-40, DS-50, DS-100, ES-10, ES-20, ES-30, ES-40, ES-50 and ES-100. The results of SEM of the fracture surfaces of DS-10 and ES-10 are illustrated in Figure 5. During testing, the samples CS-0, DS-10, DS-20, DS-30, DS-40, DS-50 and DS-100 show ductile to brittle fracture with descending order. Ductile fractured samples exhibit a white appearance and necking during failure. On the other hand, the brittle fractured surfaces of samples do not show any white appearance. A similar effect was observed when testing the samples of ES-10, ES-20, ES-30, ES-40, ES-50 and ES-100. The whitening effect was more pronounced in the case of domestic scrap. Greater numbers of domestic samples showed ductile fracture and whitening effects. On the contrary, external samples demonstrated ductile fracture on the minimum number of samples. Before SEM examination, platinum sputtering was done to minimize the charging effect of organic materials such as PVC. During examination of the different samples, black and white area, different phases, phase interaction area and phase distribution style are observed. The white area of the images indicates the tip of the protruded surface and the black area indicates the area of the valley of the fracture surface. The external fracture surface shows more black area in descending order from CS-0, DS-10 and so on. Different phases and interfaces were observed in both sets of samples. Variation in the distribution of phases and interfaces is also observed. No voids are detected. Similar results have also been reported elsewhere [26]. Phases and interfaces differences in the same sample or in different samples of fracture surface have been exhibited during SEM observation (Figure 5). For polymeric materials phase distribution is an important factor. This phase distribution is related to mechanical properties. Lack of uniform phase distribution is one of the causes of fluctuation of mechanical properties. Again the phase distribution is related to the processing technology of products. During investigation it was found that break stress along the longitudinal direction is greater than along the transverse direction.

Elemental analysis was performed on different points of the fracture surfaces of the samples CS-0, DS-10, DS-20, DS-30, DS-40, DS-50, DS-100, ES-10, ES-20, ES-30, ES-40, ES-50 and ES-100. The results of all the elements obtained using the energy 
dispersive x-ray technique in all samples containing domestic and external scrap are shown in Table 3.

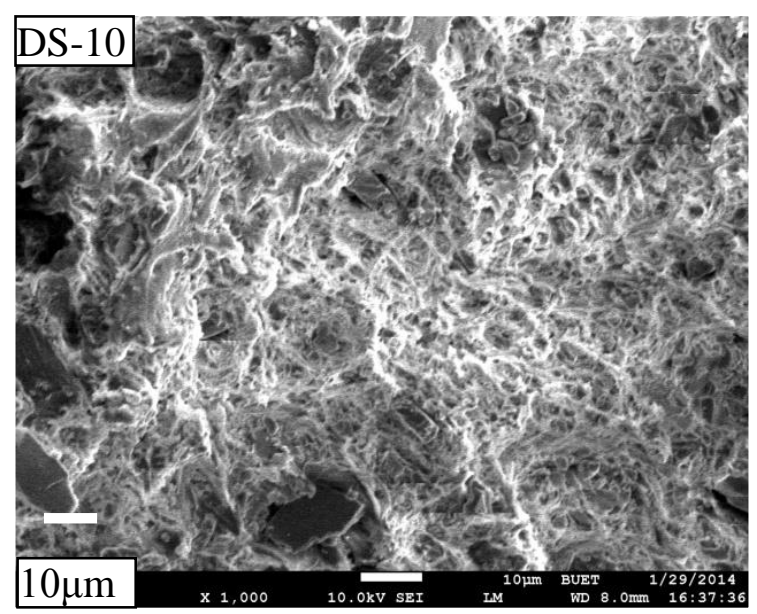

(a) DS-10

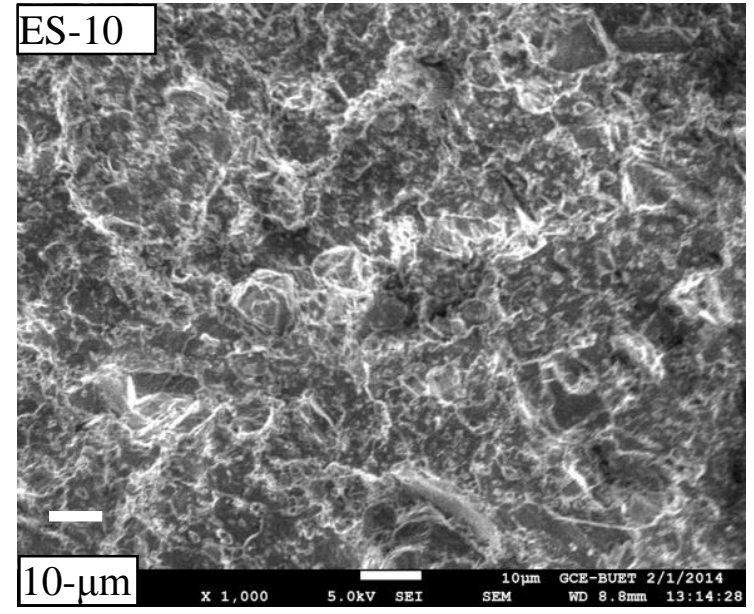

(b) ES-10

Figure 5. SEM micrograph of the fractured surfaces of samples containing domestic and external scrap designated as (a) DS-10 and (b) ES-10.

Compositional variations in different phases and interfaces of different samples have also been detected by EDS spot analysis. The compositional variations found by EDS spot analysis in samples designated as DS-10 and ES-10 are demonstrated in Figure 6 and Table 4. Phases and interfaces differences have been observed. These types of variation may be due to density difference of the elements, fusion of ingredients during hot and cold mixing, the element-detection technology and extrusion technology. In-homogeneity has also been reported by D. Braun [27]. Attempts were made to make a homogeneous compound by blending the ingredients in a high-speed rotating drum $(3500 \mathrm{rpm})$ followed by a low-speed rotating drum $(200 \mathrm{rpm})$. The mixture was then sent to the extrusion process, in which the ingredients were also mixed and extruded as a pipe. Still inhomogeneity was detected by EDS analysis. From Table 3, it is seen that there are large gaps in the range of elements. Besides, some elements such as $\mathrm{Si}, \mathrm{Fe}, \mathrm{Al}$ are generally not present in the polymeric compound. The big gaps and the presence of unexpected elements may be due to technological limitations and the presence of impurities.

Table 3. Summary of EDS spot analysis results performed on 13 different samples containing domestic and external scrap.

\begin{tabular}{llllll}
\hline Elements & Range (\%) & Elements & Range (\%) & Elements & Range (\%) \\
\hline $\mathrm{C}$ & $3.45-87.74$ & $\mathrm{Cl}$ & $0.03-55.13$ & $\mathrm{O}$ & $0.69-56.23$ \\
$\mathrm{Ca}$ & $0.03-42.51$ & $\mathrm{Cd}$ & $2.16-5.49$ & $\mathrm{~S}$ & $0.03-3.21$ \\
$\mathrm{Sb}$ & $0.02-8.34$ & $\mathrm{~Pb}$ & $0.26-31.81$ & $\mathrm{Sn}$ & $0.75-8.96$ \\
$\mathrm{Si}$ & $0.01-0.29$ & $\mathrm{Zn}$ & $1.14-25.05$ & $\mathrm{Ba}$ & $0.18-2.67$ \\
$\mathrm{Fe}$ & 1.84 & $\mathrm{Al}$ & $0.03-0.19$ & $\mathrm{Ti}$ & $0.92-1.73$ \\
\hline
\end{tabular}



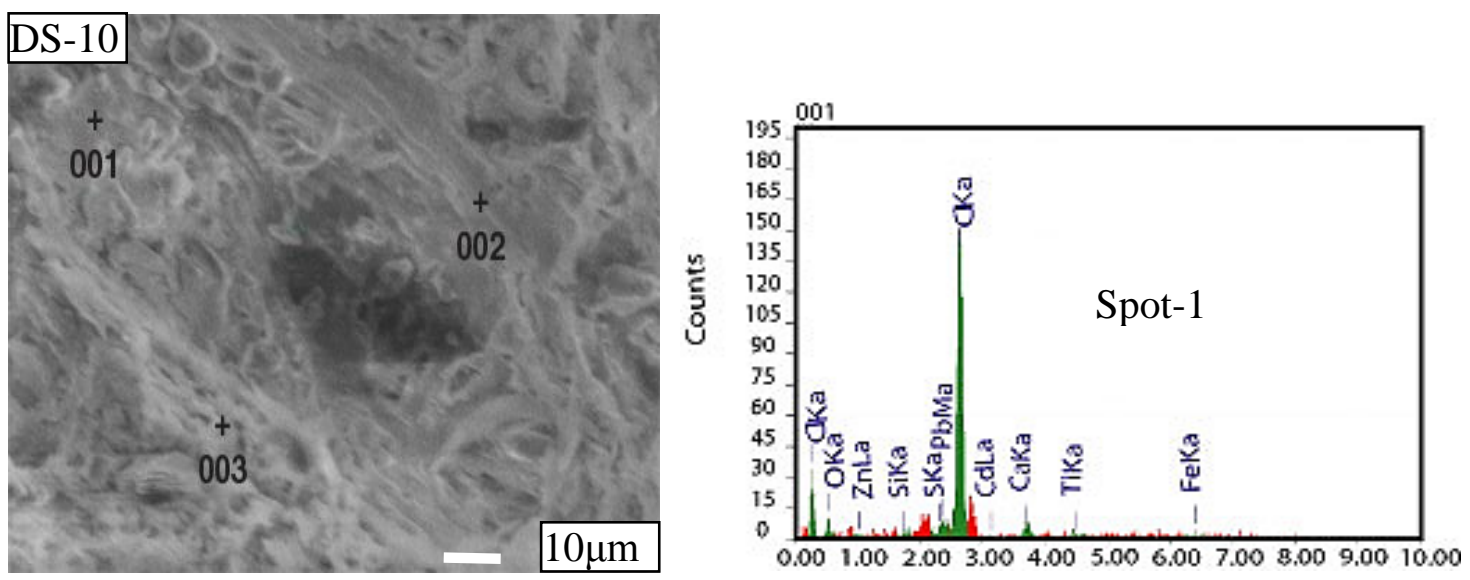

(a)
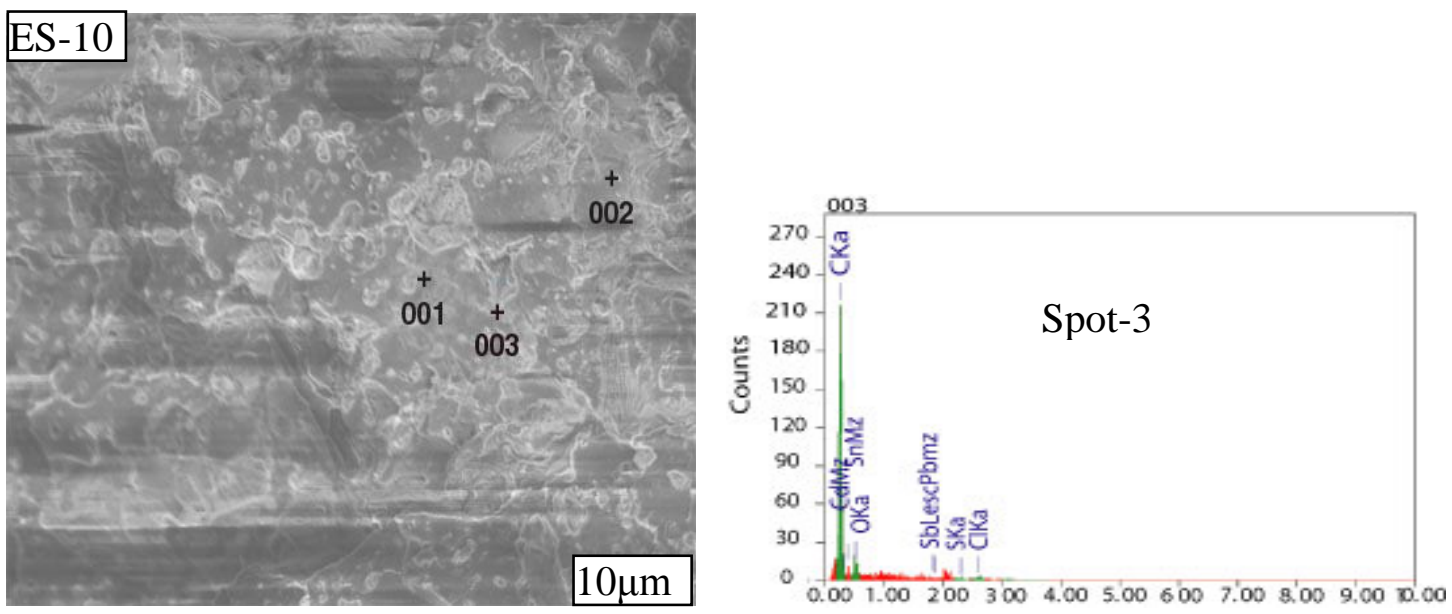

Figure 6. EDS analysis of fractured surface of sample containing $10 \mathrm{phr}$ (a) domestic scrap; (b) external scrap.

Table 4. Results of spot analysis performed by EDS on sample containing $10 \mathrm{phr}$ (a) domestic scrap; (b) external scrap.

\begin{tabular}{|c|c|c|c|c|c|c|c|c|}
\hline Spot no & $\mathrm{C}$ & $\mathrm{O}$ & $\mathrm{Si}$ & $\mathrm{Cl}$ & $\mathrm{Ca}$ & $\mathrm{Zn}$ & $\mathrm{Sn}$ & $\mathrm{Pb}$ \\
\hline \multicolumn{9}{|c|}{ Domestic scrap } \\
\hline 1 & 43.80 & 3.59 & 0.06 & 40.54 & 3.80 & 1.14 & - & 5.51 \\
\hline 2 & 31.08 & 2.20 & 0.03 & 55.13 & 4.05 & - & 1.64 & 5.75 \\
\hline 3 & 20.73 & 2.04 & 0.29 & 27.54 & 37.27 & 6.01 & - & 5.47 \\
\hline \multicolumn{9}{|c|}{ External scrap } \\
\hline Spot no & $\mathrm{C}$ & $\mathrm{O}$ & $\mathrm{Cl}$ & $\mathrm{Ca}$ & $\mathrm{Sb}$ & $\mathrm{Pb}$ & & \\
\hline 1 & 79.57 & 10.24 & 0.68 & 0.07 & 2.51 & 6.86 & & \\
\hline 2 & 43.83 & 54.83 & 0.40 & - & 0.02 & 0.26 & & \\
\hline 3 & 87.74 & 7.10 & 2.23 & - & 0.27 & 0.28 & & \\
\hline
\end{tabular}


Effect of proportion of home and external scrap on the mechanical properties of recycled PVC:

\section{CONCLUSIONS}

The effects of the quantity of domestic and external scrap on the properties of recycled uPVC products have been investigated by tensile, flexural, impact and hardness testing. From the results obtained, the following conclusion can be drawn.

i) The mechanical properties, such as break stress, \% elongation at break, flexural strength and impact strength, decrease with the increase of domestic and external scrap. It is notable that the observed values show a little fluctuation, which has been attributed to incompatibility, inhomogeneity, varying molecular weight and impurities. Deterioration in mechanical properties is found to be greater in the samples containing external scrap than in those containing domestic scrap.

ii) The hardness value of the samples does not depend on the quantity of scrap mixed.

iii) SEM shows variations of shape and the distribution of different phases. Differences in interfaces are also observed. Variation in the quantities of elements is also observed by EDS spot analysis.

From the above discussion it can be concluded that domestic scrap could be used for making pressure pipes and other proportions of external scrap could be used for making non-pressure pipes or other less important applications.

\section{RECOMMENDATIONS FOR FUTURE WORK}

i) Characterization of repeated recycling of uPVC products containing different proportions of domestic and external scrap.

ii) Study on effects of quenching, particles size, ageing, degree of gelation on the properties of recycled products containing domestic and external scrap.

iii) Effect of proportion of different fillers and adding heat stabilizer heat in the raw material mixture on mechanical properties of products.

\section{ACKNOWLEDGMENT}

The authors are grateful to Project Director, Development of Materials for Tools and Biometallic Implants for providing the facilities for this study. The financial support provided by BUET for this study is also gratefully acknowledged.

\section{REFERENCES}

[1] Paralikas J, Fysikopoulos A, Pandremenos J, Chryssolouris G. Product modularity and assembly systems: An automotive case study. CIRP Annals Manufacturing Technology. 2011;60:165-8.

[2] Plinke E, Wenk N, Wolff G, Castiglione D, Palmark M. Mechanical recycling of PVC wastes. Study for DG XI of the European Commission in cooperation with Plastic Consult (Italy) and COWI (Denmark), Basel, Milan, Lyngby. 2000.

[3] Williams EA, Williams PT. Analysis of products derived from the fast pyrolysis of plastic waste. Journal of Analytical and Applied Pyrolysis. 1997;40-41:34763. 
[4] Takoungsakdakun T, Pongstabodee S. Separation of mixed post-consumer PETPOM-PVC plastic waste using selective flotation. Separation and Purification Technology. 2007;54:248-52.

[5] Yarahmadi N, Jakubowicz I, Gevert T. Effects of repeated extrusion on the properties and durability of rigid PVC scrap. Polymer Degradation and Stability. 2001;73:93-9.

[6] Morris J. Recycling versus incineration: an energy conservation analysis. Journal of Hazardous Materials. 1996;47:277-93.

[7] Jaksland C, Rasmussen E, Rohde T. A new technology for treatment of PVC waste. Waste Management. 2000;20:463-7.

[8] Dalen MB, Nasir T. Plastic Waste Recycling. World Science Journal. 2009;4:710.

[9] Al-Salem SM, Lettieri P, Baeyens J. Recycling and recovery routes of plastic solid waste (PSW): A review. Waste Management. 2009;29:2625-43.

[10] Al-Salem SM, Lettieri P, Baeyens J. The valorization of plastic solid waste (PSW) by primary to quaternary routes: From re-use to energy and chemicals. Progress in Energy and Combustion Science. 2010;36:103-29.

[11] Dodbiba G, Sadaki J, Okaya K, Shibayama A, Fujita T. The use of air tabling and triboelectric separation for separating a mixture of three plastics. Minerals Engineering. 2005; 18:1350-60.

[12] Gonzalez N, Mugica A, José Fernandez-Berridi M. Application of high resolution thermogravimetry to the study of thermal stability of poly(vinyl chloride) resins. Polymer Degradation and Stability. 2006;91:629-33.

[13] de Marco I, Caballero BM, López A, Laresgoiti MF, Torres A, Chomón MJ. Pyrolysis of the rejects of a waste packaging separation and classification plant. Journal of Analytical and Applied Pyrolysis. 2009;85:384-91.

[14] Aznar MP, Caballero MA, Sancho JA, Francés E. Plastic waste elimination by co-gasification with coal and biomass in fluidized bed with air in pilot plant. Fuel Processing Technology. 2006;87:409-20.

[15] Asanuma M, Ariyama T. Recycling of waste plastics in blast furnace. Journal of Japan Institute of Energy. 2004;83:252-6.

[16] Kato K, Fukuda K, Takamatsu N. Waste plastics recycling technology using coke ovens. Journal-Japan Institute of Energy. 2004;83:248-51.

[17] Wienaah M. Sustainable plastic waste management-a case of Accra, Ghana, KTH land and water resource engineering, TRITA-LWR (Master thesis). LWREX-07-10; 2007.

[18] Sombatsompop N, Sungsanit K. Processability, rheology, and thermal, mechanical, and morphological properties of postconsumer poly(vinyl chloride) bottles and cables. Journal of Applied Polymer Science. 2003;89:2738-48.

[19] Ditta AS, Wilkinson AJ, McNally GM, Murphy WR. A study of the processing characteristics and mechanical properties of multiple recycled rigid PVC. Journal of Vinyl and Additive Technology. 2004;10:174-8.

[20] Arnold JC, Maund B, Isaac DH. The mechanical properties of recycled PVC bottle compounds. Journal of Materials Processing Technology. 1996;56:475-81.

[21] Hallam MA, Pollard G, Ward IM. Relationship between tensile strength and molecular weight of highly drawn polyethylenes. Journal of Materials Science Letters. 1987;6:975-6. 
[22] Smith P, Lemstra PJ, Pijpers JPL. Tensile strength of highly oriented polyethylene. II. Effect of molecular weight distribution. Journal of Polymer Science: Polymer Physics Edition. 1982;20:2229-41.

[23] Strapasson R, Amico SC, Pereira MFR, Sydenstricker THD. Tensile and impact behavior of polypropylene/low density polyethylene blends. Polymer Testing. 2005;24:468-73.

[24] Fillot L-A, Hajji P, Gauthier C, Masenelli-Varlot K. Thermomechanical history effects on rigid PVC microstructure and impact properties. Journal of Applied Polymer Science. 2007;104:2009-17.

[25] Wenguang M, Mantia FPL. Processing and mechanical properties of recycled PVC and of homopolymer blends with virgin PVC. Journal of Applied Polymer Science. 1996;59:759-67.

[26] Lin H-R, Lin C-T. Mechanical Properties and Morphology of Recycled. Plastic Wastes by Solution Blending. Polymer-Plastics Technology and Engineering. 1999;38:1031-50.

[27] Braun D. Recycling of PVC. Progress in Polymer Science. 2002;27:2171-95. 